\title{
DIAGNÓSTICO SOBRE CONTAMINAÇÃO DAS ÁGUAS SUBTERRÂNEAS NA ÁREA DO PARQUE ESTADUAL DO UTINGA, BELÉM-PA, PELOS MÉTODOS ELÉTRICO E ELETROMAGNÉTICO
}

\author{
Vânia Eunice Bahia', José Gouvêa Luiz², Luiz Rogério Bastos Leal ${ }^{1}$, \\ Norbert Fenzl ${ }^{3}$ e Gundisalvo Piratoba Morales ${ }^{4}$
}

Recebido em 24 novembro, 2010 / Aceito em 11 outubro, 2011 Received on November 24, 2010 / Accepted on October 11, 2011

\begin{abstract}
In the present work, geophysical measurements and drilling of monitoring wells were performed to evaluate the possibility of contamination in the Utinga State Park, where are found two large surface water reservoirs responsible for the supply of the metropolitan area of Belém, Pará State, Brazil. The applied geophysical methodology, involving electromagnetic measures (Slingram) and vertical electrical sounding (VES), revealed the presence of geological layers with different electrical characteristics, allowing the identification of areas with more conductive layers associated to clay/contamination and sand layers associated to less conductivity, as well the presence of groundwater near the surface. The results allowed to establish a pattern of subsurface characterization that could be compared and correlated with information from the geological and hydrogeological descriptions obtained in monitoring wells, showing a strong correlation between data.
\end{abstract}

Keywords: environmental geophysics, groundwater, Utinga State Park.

RESUMO. No presente trabalho foram realizados levantamentos geofísicos e a perfuração de piezômetros para avaliar as características geológicas e a possibilidade de contaminação no Parque Estadual do Utinga, que contém dois grandes reservatórios de águas superficiais, responsáveis pelo abastecimento da região metropolitana de Belém-PA. A metodologia geofísica aplicada envolveu medidas eletromagnéticas (sistema Slingram) e Sondagens Elétricas Verticais (SEVs), que evidenciaram a presença de camadas geológicas com características elétricas diferentes, permitindo a identificação de zonas mais condutoras associadas a camadas argilosas e menos condutoras associadas a camadas arenosas, além da presença do nível freático próximo à superfície. Foi estabelecido um padrão de caracterização da subsuperfície que permitiu comparar e correlacionar os resultados com as informações provenientes das descrições geológicas e hidrogeológicas obtidas em piezômetros, demonstrando uma forte correspondência entre os dados.

Palavras-chave: geofísica ambiental, água subterrânea, Parque Estadual do Utinga.

\footnotetext{
${ }_{1}^{1}$ Universidade Federal da Bahia - UFBA / Curso de Pós-Graduação em Geologia Ambiental, Hidrogeologia e Recursos Hídricos, Rua Barão de Geremoabo, s/n, Campus Universitário de Ondina, 40170-280 Salvador, BA, Brasil. Tel.: (71) 3283-8534; Fax: (71) 3283-8501 - E-mails: vbahia@ufpa.br; Irogerio@ufba.br

2 Universidade Federal do Pará - UFPA / Departamento de Geofísica, Caixa Postal 479, Rua Augusto Corrêa, 1, Campus do Guamá, 66075-110 Belém, PA, Brasil. Tel.: (91) 3183-1671; Fax: (91) 3183-1609 - E-mail: gouvea@ufpa.br

3 Universidade Federal do Pará - UFPA / Núcleo de Meio Ambiente, Caixa Postal 479, Rua Augusto Corrêa, 1, Campus do Guamá, Setor Profissional, 66075-110 Belém, PA, Brasil. Tel.: (91) 3201-7652; Fax: (91) 3201-7772 - E-mail: norbert@ufpa.br

${ }^{4}$ Universidade Estado do Pará - UEPA / Centro de Ciências Naturais e Tecnologia, Travessa Enéas Pinheiro, 2626 - Marco, 66095-100 Belém, PA, Brasil. Tel.: (91) 3276-4011; Fax: (91) 3276-9517 - E-mail: gundy_morales@yahoo.com.br
} 


\section{INTRODUÇÃo}

Em Belém, o maior município da Amazônia, com uma população estimada de 1.393.399 habitantes (IBGE, 2010), são visíveis as formas de degradação à natureza. 0 município cresce de forma confusa e caótica e, assim, problemas ambientais decorrentes da expansão da metrópole se configuram sobre o meio natural oriundos principalmente do crescimento urbano, havendo por isso um quadro socioambiental permissivo e favorecedor de agravos à saúde da população, que ocorrem em grande número, gravidade e proporção.

0 Parque Estadual do Utinga (PEUt) é uma área de preservação onde se encontram os lagos Bolonha e Água Preta, principais mananciais de abastecimento da Região Metropolitana de Belém (RMB). Em decorrência da urbanização crescente e desordenada que se verifica nos municípios da RMB, surgem bairros, conjuntos residenciais e multiplicação de favelas em suas áreas adjacentes, em sua maioria desprovidos de saneamento básico, constituindo-se em fonte potencial de contaminação via subsuperfície dos recursos hídricos do PEUt.

Há, portanto, a necessidade de conhecer a distribuição litológica da subsuperfície desta área de preservação, visando estimar a possibilidade de contaminação proveniente da degradação ambiental em suas proximidades.

Como a condutividade elétrica de uma rocha é basicamente determinada pelo conteúdo e salinidade de seu eletrólito, pelo volume e conectividade de seus espaços vazios e pela proporção de minerais portadores de uma condutividade superficial dispersos na sua matriz de sólidos, os métodos elétricos se apresentam eficientes na hidrogeologia e em estudos de poluição subterrânea (Ward, 1990; Lima et al., 1995; Benson et al., 1997).

Um estudo por meio de piezômetros no PEUt, torna-se economicamente proibitivo devido à extensa área (cerca de 1.340 ha) a ser investigada. Por isso, optou-se por aplicar metodologia geofísica e perfurar um número reduzido de piezômetros, que serviram tanto para verificar as respostas geofísicas, como para a realização de ensaios hidrogeológicos e monitoramento da qualidade das águas dos aquíferos.

\section{LOCALIZAÇÃO DA ÁREA DE ESTUDO}

A RMB abrange os municípios de Belém, que tem como principais distritos Icoaraci e Mosqueiro; os municípios de Marituba, Benevides, Santa Bárbara, além de Ananindeua, que é contíguo ao de Belém.

A cidade de Belém está inserida na microrregião Guajarina no Estado do Pará, com uma área territorial de 736 km². Limita-se pela baia de Marajó até o extremo oriental da ilha de Mosqueiro; ao sul, pelo rio Guamá, até a confluência com o rio Mojú; a oeste, pelas baías do Guajará, Santo Antônio e Marajó.

0 PEUt está localizado em uma área delimitada por um polígono irregular (Fig. 1). Ao norte está limitado pelo igarapé Água Cristal, afluente esquerdo da microbacia do igarapé São Joaquim pertencente à bacia do igarapé do Una; ao sul pelo rio Guamá; a leste pela bacia do rio Aurá e a oeste pela microbacia do igarapé Tucunduba, afluente do rio Guamá. No PEUt estão os lagos Bolonha e Água Preta, que são formados pelas águas provenientes de nascentes e "igarapés" próximos e têm seu volume reforçado através de uma adutora que leva água do rio Guamá ao lago Água Preta, que por sua vez é ligado ao lago Bolonha por um canal.

\section{CARACTERÍSTICAS GEOLÓGICAS E HIDROGEOLÓGICAS}

A subsuperfície da RMB é constituída por sedimentos e rochas sedimentares sobrejacentes a um substrato granito-gnaíssico. A porção sedimentar é formada pelas seguintes unidades geológicas: Formação Pirabas, Grupo Barreiras, Grupo Pós-Barreiras e Aluviões. Esse pacote sedimentar pertence à bacia da foz do Amazonas e pode atingir mais de $4.000 \mathrm{~m}$ de espessura (IDESP, 1980).

Segundo Farias et al. (1992), a área do PEUt e seus arredores são formados em quase sua totalidade por sedimentos argiIosos e arenosos de origem continental da unidade Pós-Barreiras (Quaternário), constituindo o aquífero de mesmo nome, considerado o principal da RMB. Essas unidades aquíferas possuem espessura de cerca de $20 \mathrm{~m}$, localizam-se geralmente na parte superior de terreno e com pequena distribuição espacial. Na área estudada do PEUt, a profundidade do nível freático, medida em piezômetros, apresentou uma variação entre $2,7 \mathrm{~m}$ e $10 \mathrm{~m}$.

Predominam na área de estudo, solos do tipo Latossolo Amarelo Álico, seguido do Podzólico Hidromórfico Álico (Vieira \& Santos, 1987). Adjacente à área estudada há uma grande área devastada pela extração de material de construção, que apresenta confinamento de águas superficiais pontuais em toda sua extensão.

0 solo natural da área, em sua grande parte, é caracterizado por camadas do tipo argilo-arenoso em que a declividade natural do terreno indica um caimento no sentido norte-sul e leste-sul, 0 que proporciona 0 escoamento das águas superficiais em direção aos lagos Água Preta e Bolonha, igarapés e ao Rio Guamá.

\section{METODOLOGIA}

A área de estudo no PEUt foi investigada com os métodos geofísicos eletromagnéticos (medidas de fase e quadratura) e eletror- 

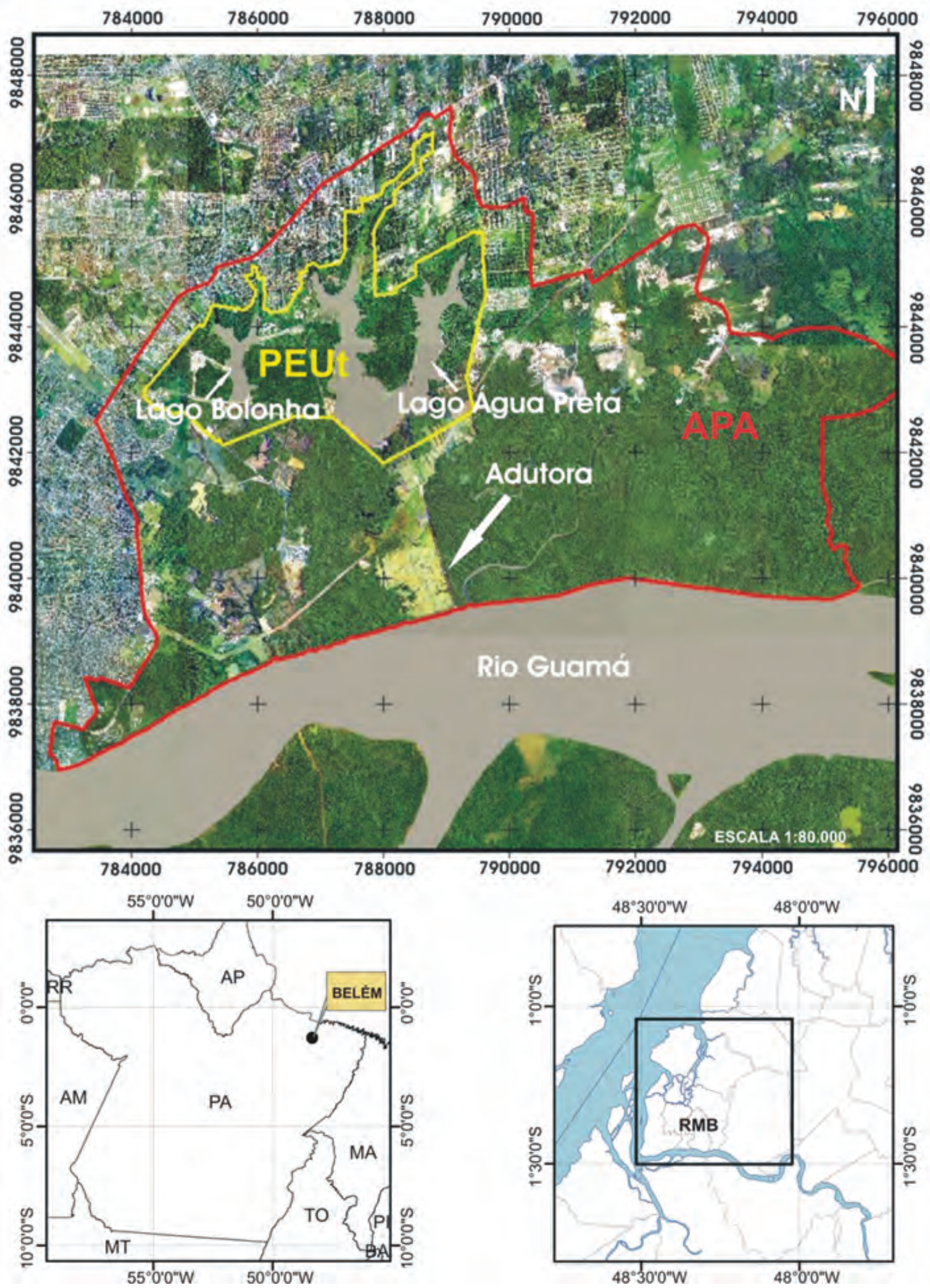

Figura 1 - Mapa de localização da área de estudo. 


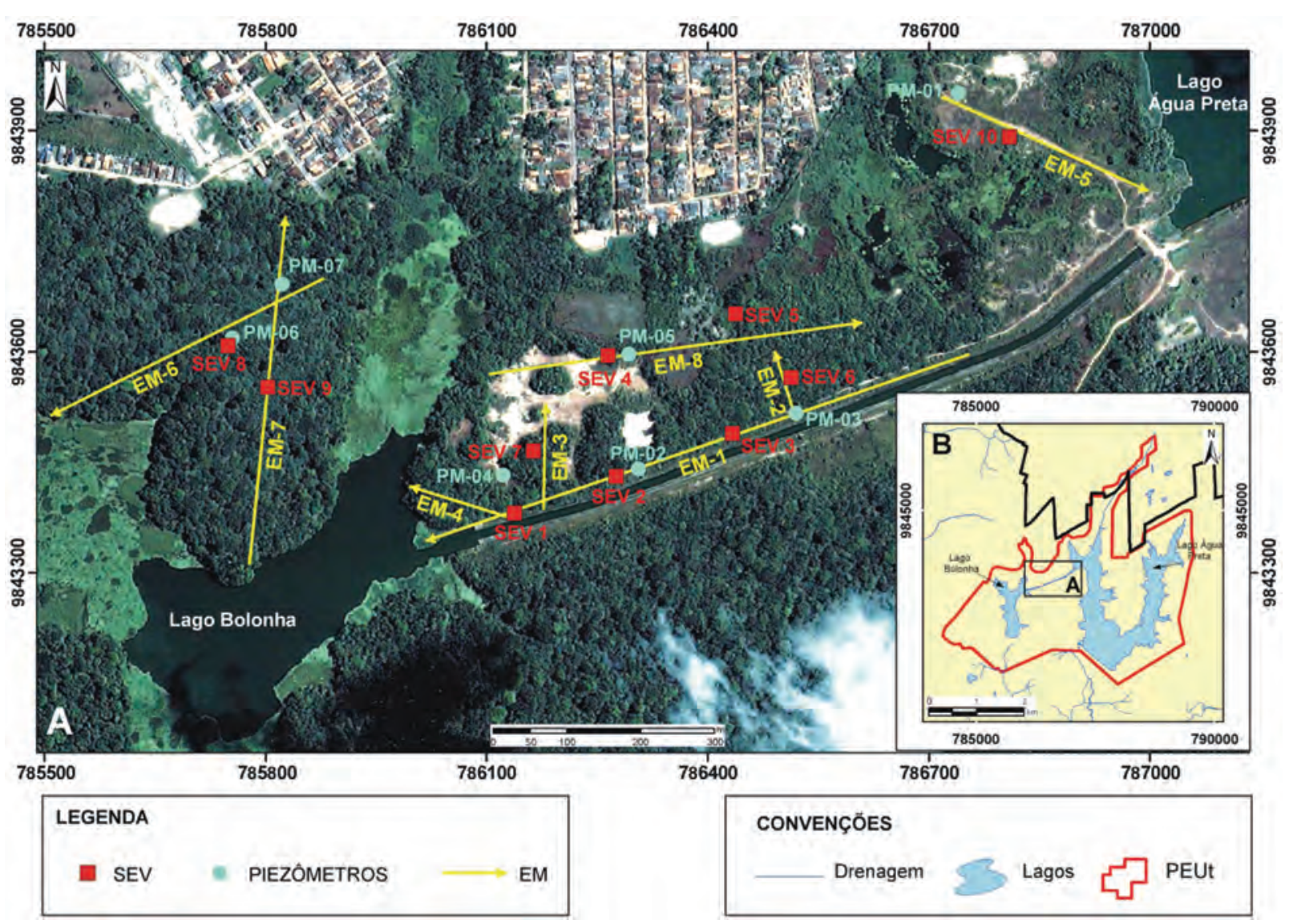

Figura 2 - Localização dos perfis eletromagnéticos, SEVs e piezômetros.

resistividade (medidas de resistividade aparente) e piezômetros com profundidades inferiores a $20 \mathrm{~m}$.

\section{Método eletromagnético}

Foram realizados na área de estudo, oito perfis de medidas eletromagnéticas (fase e quadratura) com 0 Sistema Slingram MAX MIN I na configuração coplanar horizontal (Fig. 2). As medidas foram feitas em oito frequências $(110,220,440,880,1760,3520$, 7040 e 14080 Hz). A distância entre as bobinas transmissora e receptora foi igual a $50 \mathrm{~m}$ e 0 espaçamento entre as medidas foi de $25 \mathrm{~m}$.

As componentes em fase e em quadratura foram combinadas através da Equação (1):

$$
Z=\sqrt{F^{2}+Q^{2}},
$$

sendo $Z$ o módulo da razão entre os campos magnéticos primário e secundário, $F$ o valor da componente em fase e $Q 0$ valor da componente em quadratura.

0 valor de $Z$ foi então representado de modo a se obter a sua variação com a frequência. Para, isso em cada posição de medida, os valores de $Z$ foram colocados em um eixo vertical e a seguir correlacionados lateralmente, traçando-se contornos de isovalores. Esse tipo de representação constitui uma pseudoseção da subsuperfície, pois permite que se visualize o comportamento de $Z$ nas direções horizontal e vertical abaixo das posições de medidas, uma vez que a profundidade de investigação depende da frequência (frequências mais altas estão relacionadas com menor profundidade e frequências mais baixas com maior profundidade). Nesta representação, os valores maiores de $Z$ são associados às zonas mais condutoras da subsuperfície (por exemplo, as zonas argilosas) enquanto os menores valores são associados às zonas menos condutoras (zonas arenosas) (Silva, 2002).

\section{Método da eletrorresistividade}

Com o método da eletrorresistividade foram realizadas medidas de resistividade aparente usando a técnica de Sondagem Elétrica Vertical (SEV), que permite que se investigue a distribuição da resistividade com a profundidade. As SEVs foram realiza- 


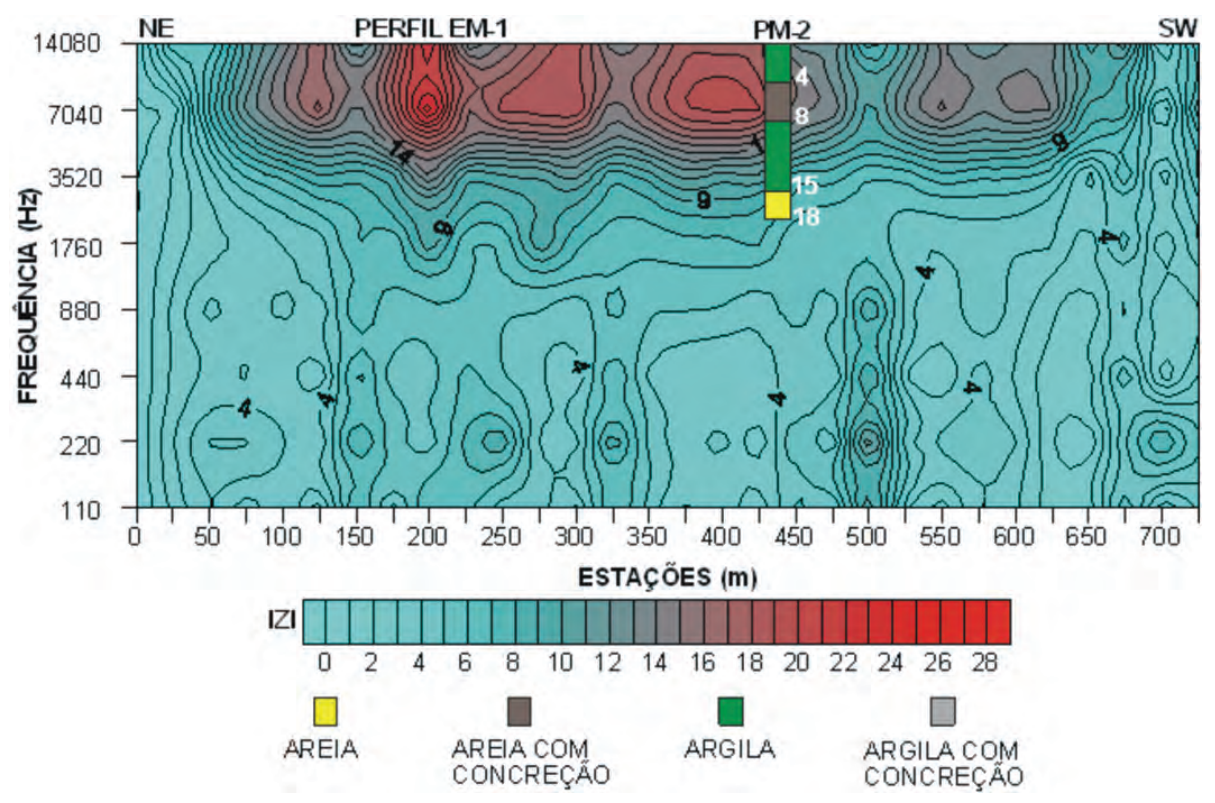

Figura 3 - Contorno de isovalores do módulo do campo magnético ( $Z$ ) versus a frequência (pseudo-seção) para o perfil EM-1.

das com arranjo Schlumberger, com abertura máxima de $A B / 2$ igual a $180 \mathrm{~m}$. Foram executadas $10 \mathrm{SEV}$ s em pontos estrategicamente selecionados no início dos trabalhos, de modo a abranger a área identificada como a mais atingida pela expansão urbana (Fig. 2).

As SEVs foram interpretadas usando programa desenvolvido por Zohdy \& Bisdorf (1989), que processa a curva de medidas digitalizando-a e estabelecendo um modelo de distribuição da resistividade associado a um número de camadas igual ao número de pontos usados na digitalização. Esse tipo de modelo mostra maior detalhe na variação da resistividade com a profundidade do que os modelos interpretativos geralmente obtidos com outros programas.

\section{Piezômetros}

Foram perfurados sete piezômetros com o objetivo de estabelecer comparações com os levantamentos geofísicos e os locais para perfuração foram baseados nas possíveis variações litológicas indicadas pelas medidas geofísicas (Fig. 2). Na construção dos piezômetros, foram seguidas as normas da Associação Brasileira de Normas Técnicas - ABNT (1997), sendo coletadas amostras de sedimentos a cada metro de profundidade.

\section{RESULTADOS E DISCUSSÃO}

A seguir são apresentadas as análises da aplicação dos resultados dos métodos eletromagnético e da eletrorresistividade. Du- rante essas análises é feita uma correlação com as informações obtidas a partir dos piezômetros, numa tentativa de minimizar a ambiguidade na interpretação geofísica e proporcionar resultados mais confiáveis.

\section{Medidas eletromagnéticas}

0 perfil EM-1 cobriu a extensão de $725 \mathrm{~m}$ e foi executado no sentido NE-SW (Fig. 2), que percorre a linha do canal que interliga os dois principais mananciais da área de estudo - Lago Água Preta e Lago Bolonha. Os contornos de isovalores do módulo do campo estão representados na Figura 3, onde também foi justaposto, para fins de comparação, o perfil litológico do piezômetro PM-2.

É bem evidenciado na representação da Figura 3 zonas condutoras (tons avermelhados) em quase todo o perfil EM-1, sendo possível que tal condutividade esteja relacionada com material argiloso em subsuperfície ou à presença de água com condutividade elevada, uma vez que ocorre material arenoso no intervalo de profundidade 4-8 m do piezômetro PM-2.

Percebe-se ainda, que a zona de maior condutividade concentra-se nas frequências maiores, que correspondem, de acordo com 0 piezômetro PM-2, às profundidades inferiores a $15 \mathrm{~m}$. É possível que o contorno de isovalor 10, mostrado na figura, possa ser correlacionado ao topo dos sedimentos lateríticos menos condutivos do Grupo Barreiras. Nesse caso, os valores de contorno maiores que 10 estariam associados a sedimentos mais condutivos, provavelmente do Pós-Barreiras. 


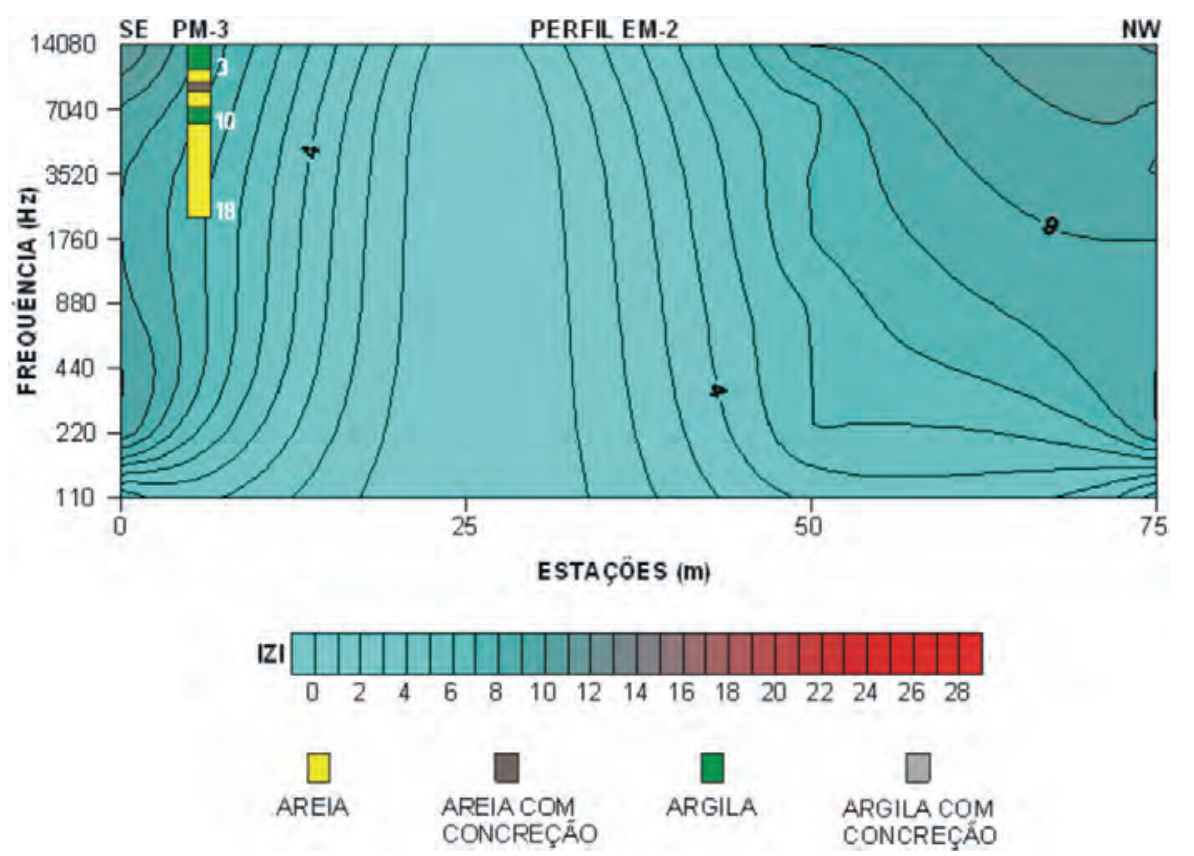

Figura 4 - Contorno de isovalores do módulo do campo magnético $(Z)$ versus a frequência (pseudo-seção) para o perfil EM-2.

0 perfil EM-2 foi realizado no sentido SE-NW, iniciando às proximidades do perfil EM-1 e finalizando próximo ao perfil EM-8, cobrindo uma distância de 75 m (Fig. 2). Este perfil foi interrompido aos $75 \mathrm{~m}$ devido à presença de um canal inundado por água pluvial, que influenciou nas medidas coletadas a partir desta posição. As observações geológicas de superfície ao longo deste perfil, permitiram identificar a presença de um terreno bastante úmido no decorrer de todo 0 seu percurso. A Figura 4 mostra as respostas obtidas para o módulo do campo, juntamente com o perfil litológico do piezômetro PM-3.

Os valores obtidos mostram uma predominância de material mais resistivo (tons azuis) ao longo de todo o perfil, com as zonas mais condutoras distribuídas no início e final do perfil, provavelmente devido à presença de água no solo, bem evidenciada superficialmente. Este perfil indica ainda, um aumento de condutividade (aumento da argilosidade) em direção à zona residencial localizada na extremidade NW do perfil. 0 piezômetro PM-3 localizado próximo à extremidade SE do perfil mostra uma predominância de material arenoso, correlacionando com a resposta geofísica.

0 caminhamento EM-3 foi realizado no sentido N-S, paralelo ao perfil EM-2, cobriu a extensão de $175 \mathrm{~m}$ e à semelhança do perfil EM-2 foi interrompido em um pequeno canal inundado (Fig. 2). As medidas obtidas neste perfil encontram-se representadas na Figura 5, junto com o perfil litológico do piezômetro PM-4. A representação do módulo do campo indica zonas con- dutivas, que se estendem a profundidade maior do que $18 \mathrm{~m}$, conforme indica o perfil do piezômetro PM-4.

0 perfil EM-4 se inicia no canal que interliga os dois lagos e tem 125 m de extensão, tendo sido executado no sentido SE-NW (Fig. 2). Os valores medidos, representados na forma de módulo do campo na Figura 6, sugerem: (a) zona arenosa entre as posições 0 e 25 m; (b) uma predominância de zonas fortemente condutoras a partir da posição $25 \mathrm{~m}$, que se estendem em profundidade, já que foram detectadas nas baixas frequências. A localização desse perfil sugere que essas zonas condutoras sejam provavelmente causadas pela invasão de água proveniente do lago Bolonha e do canal que o liga ao lago Água Preta.

0 perfil EM-5 é o caminhamento localizado mais a leste da área de estudo, realizado no sentido NW-SE, mais precisamente nas proximidades da estrada de acesso entre os mananciais e uma zona de ocupação urbana (Fig. 2). 0 perfil tem 275 m de extensão e os valores do módulo do campo obtidos ao longo deste caminhamento estão representados na Figura 7, juntamente com o perfil litológico do piezômetro PM-1.

Os valores sugerem a existência de zonas condutoras na posição $50 \mathrm{~m}$ e entre as posições $200 \mathrm{~m}$ e $275 \mathrm{~m}$. A zona condutora localizada na posição $50 \mathrm{~m}$ é bem evidente nas mais altas frequências e, portanto, associada às menores profundidades. 0 piezômetro PM-1, localizado nessa zona indica que a maior condutividade nesse local provém de material argiloso observado entre as profundidades $3 \mathrm{~m}$ e $10 \mathrm{~m}$. Na zona loca- 

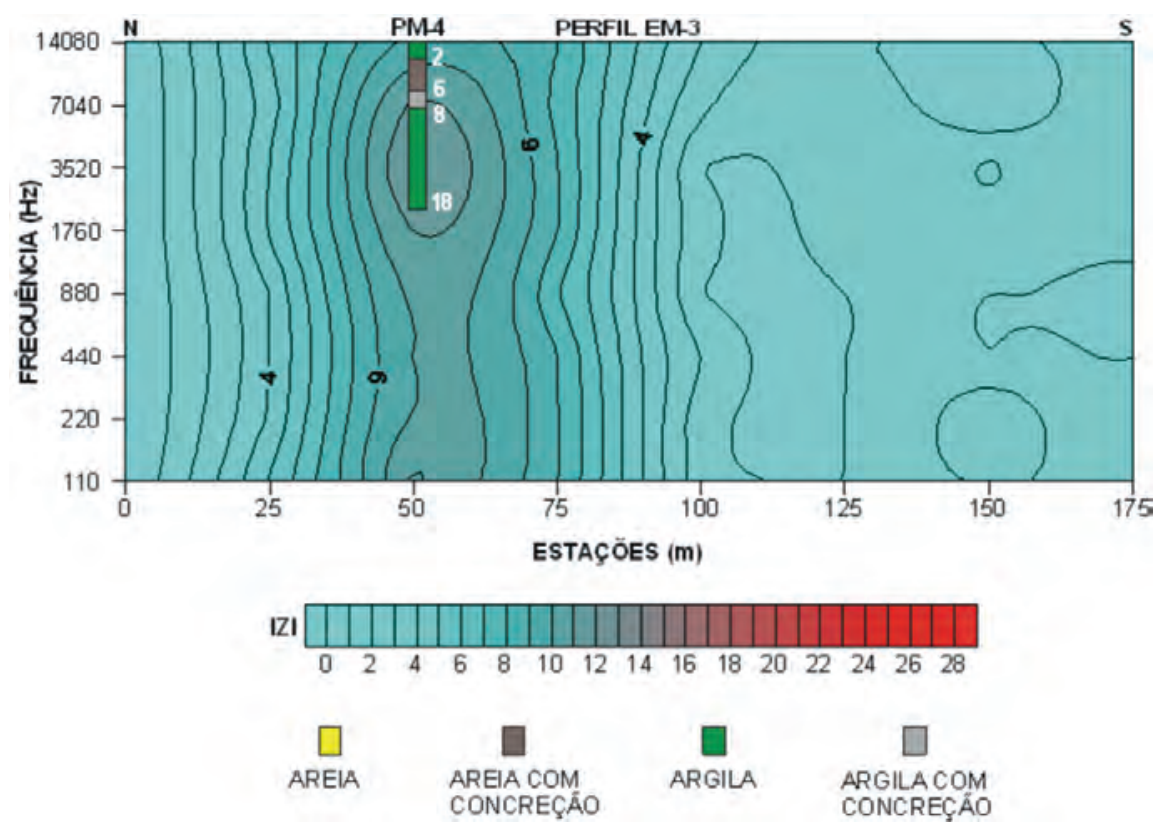

Figura 5 - Contornos de isovalores do módulo do campo magnético (Z) versus a frequência (pseudo-seção) para o perfil EM-3.

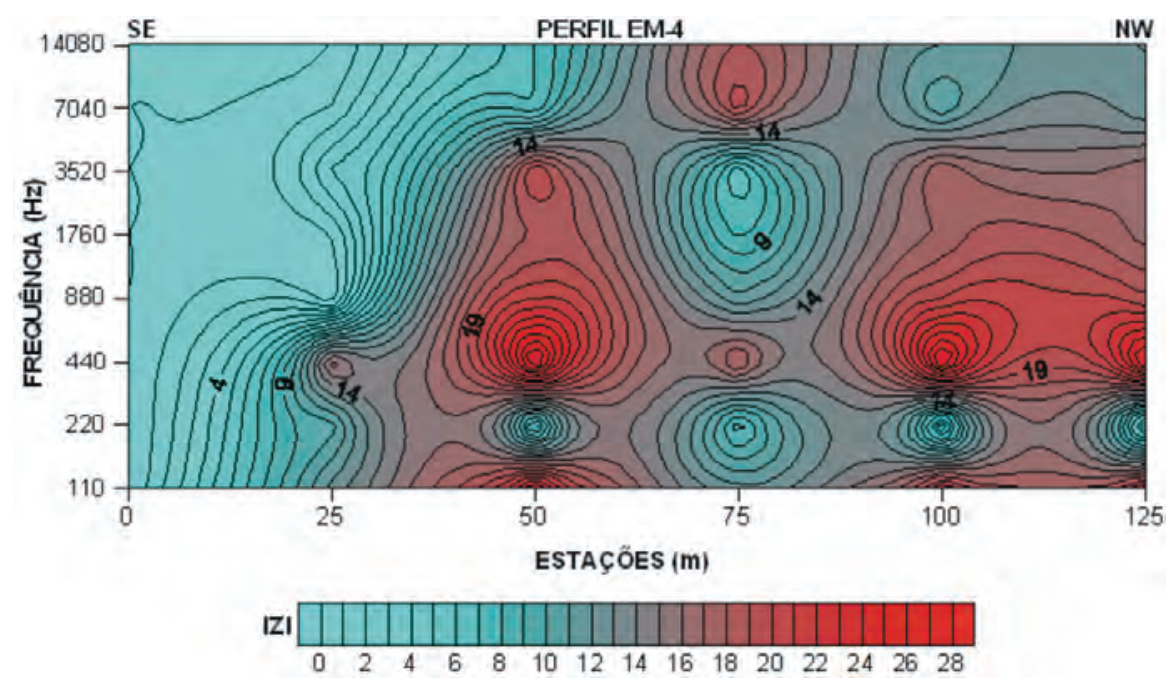

Figura 6 - Contorno de isovalores do módulo do campo magnético ( $Z$ ) versus a frequência (pseudo-seção) para o perfil EM-4.

lizada entre as posições $200 \mathrm{~m}$ e $250 \mathrm{~m}$ do perfil, as curvas apresentam um comportamento similar ao da posição $50 \mathrm{~m}$, porém de menor intensidade.

Os valores sugerem a existência de zonas condutoras na posição $50 \mathrm{~m}$ e entre as posições $200 \mathrm{~m}$ e $275 \mathrm{~m}$. A zona condutora localizada na posição $50 \mathrm{~m}$ é bem evidente nas mais altas frequências e, portanto, associada às menores profundidades. 0 piezômetro PM-1, localizado nessa zona indica que a maior condutividade nesse local provém de material argiloso observado entre as profundidades $3 \mathrm{~m}$ e $10 \mathrm{~m}$, com contribuição da condutividade da água $(55,8 \mu \mathrm{S} / \mathrm{cm}$, tanto no período de chuva, como no de estiagem). Na zona localizada entre as posições $200 \mathrm{~m}$ e $250 \mathrm{~m}$ do perfil, as curvas apresentam um comportamento similar ao da posiçã̃o $50 \mathrm{~m}$, porém de menor intensidade, talvez com contribuição apenas da argilosidade.

Os valores do módulo do campo obtidos ao longo do perfil EM-6 estão representados na Figura 8 junto com a litologia do piezômetro PM-6. 0 perfil cobre uma distância de $425 \mathrm{~m}$ no sentido NE-SW, terminando às margens do Lago Bolonha (Fig. 2). 

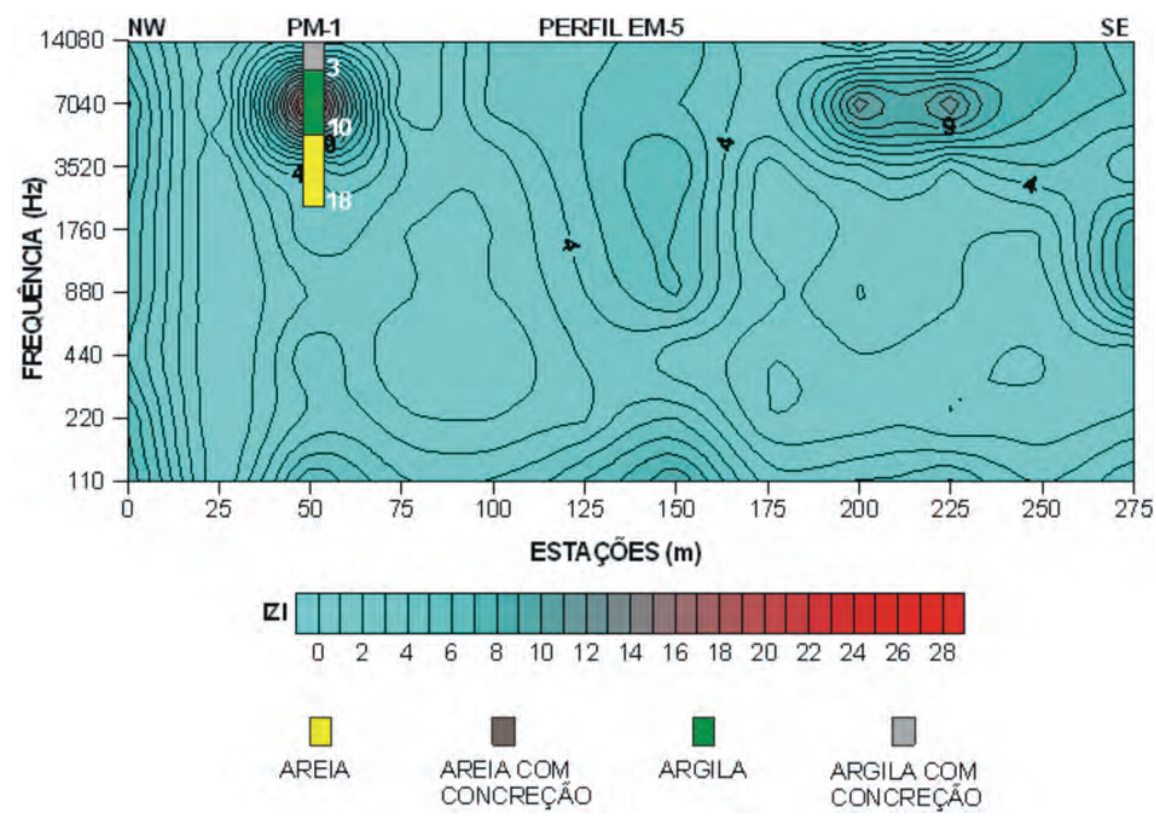

Figura 7 - Contorno de isovalores do módulo do campo magnético $(Z)$ versus a frequência (pseudo-seção) para o perfil EM-5.
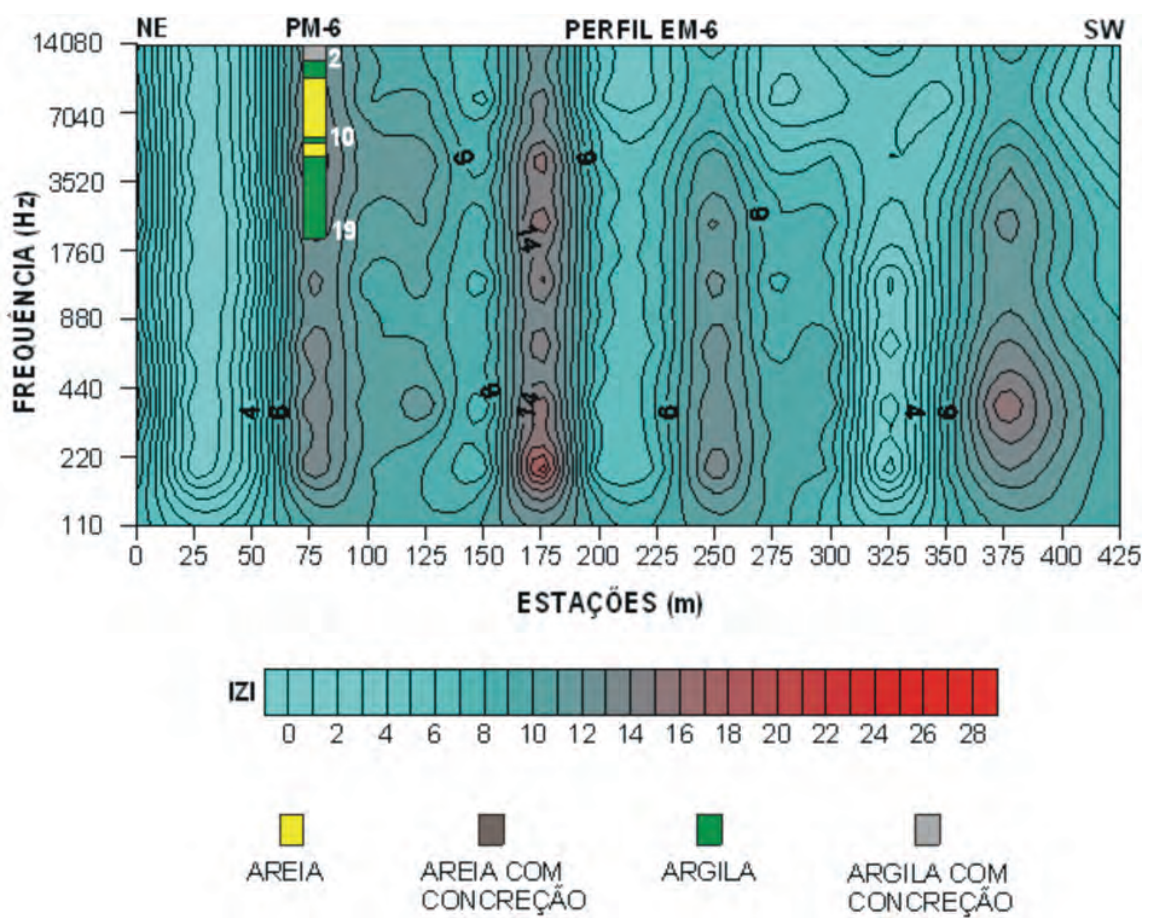

Figura 8 - Contorno de isovalores do módulo do campo magnético ( $Z$ ) versus a frequência (pseudo-seção) para o perfil EM-6.

Os valores relacionados ao perfil EM-6 sugerem a existência de zonas condutoras em vários locais, distribuídas em profundidades variadas. 0 piezômetro PM-6 localizado sobre a zona identificada na posição $75 \mathrm{~m}$ mostra uma boa quantidade de argila, indicando um padrão eletromagnético condutivo.
0 perfil EM-7 foi realizado no sentido S-N, cobrindo uma distância de $425 \mathrm{~m}$. 0 perfil iniciou às margens do lago Bolonha e foi concluído em uma área de ocupação urbana (Fig. 2). Este perfil cruza a extremidade NE do perfil EM-6, às proximidades do piezômetro PM-7 (Fig. 9). 


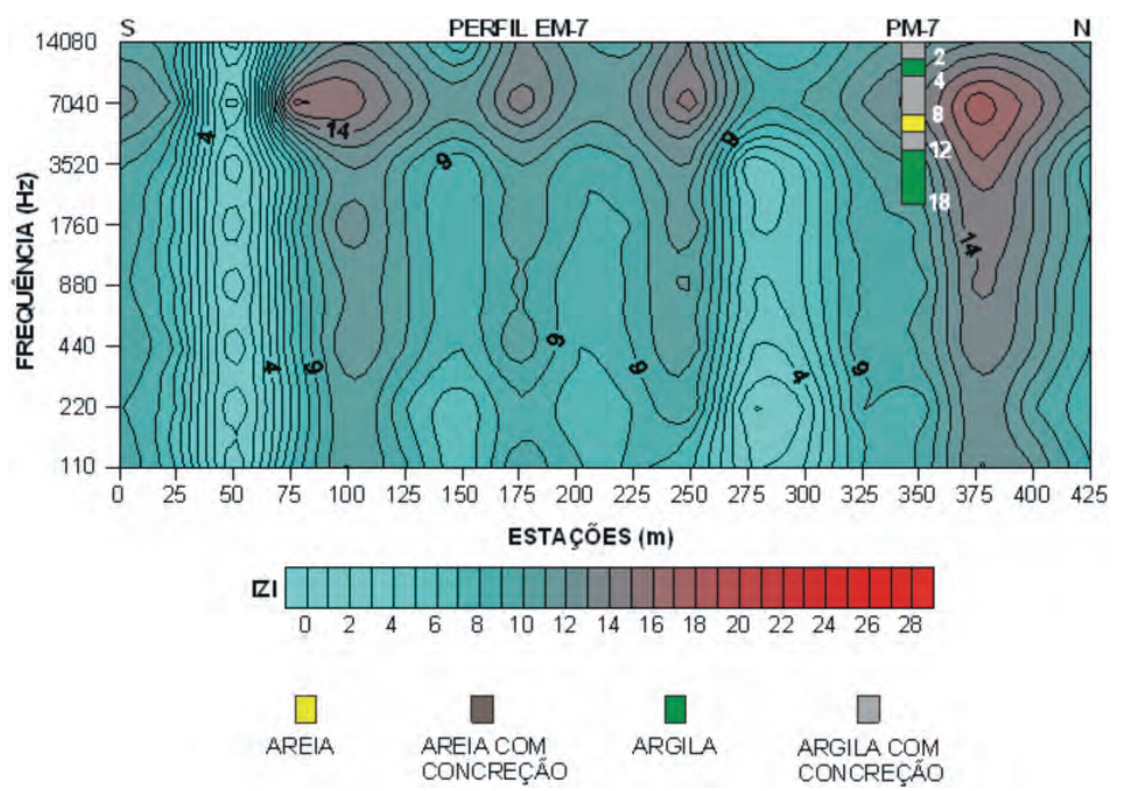

Figura 9 - Contorno de isovalores do módulo do campo magnético ( $Z$ ) versus a frequência (pseudo-seção) para o perfil EM-7.

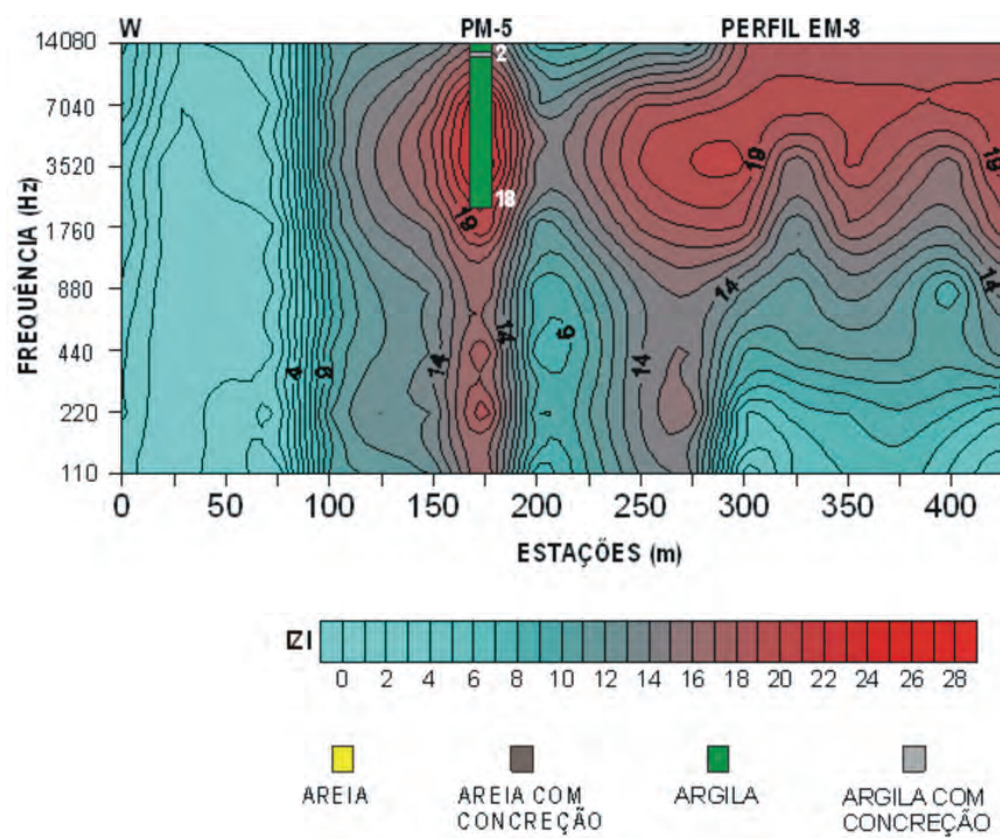

Figura 10 - Contorno de isovalores do módulo do campo magnético ( $Z$ ) versus a frequência (pseudo-seção) para o perfil EM-8.

As observações geológicas de superfície ao longo do perfil EM-7 permitiram identificar zonas condutoras que concordam com as respostas obtidas para as componentes do módulo do campo. Essas zonas, embora sejam bem evidentes em quase todas frequências, apresentam maiores valores para as frequências mais altas. A presença de argilas com concreção, identificadas no piezômetro PM-7, podem ter contribuído para tornar o padrão mais condutivo.
0 perfil EM-8 foi realizado no sentido W-E, iniciando às margens do lago Bolonha (Fig. 2). 0 perfil foi interrompido aos $475 \mathrm{~m}$ devido à presença de um canal inundado por água pluvial, que influenciou nas medidas coletadas a partir desta posição. Os valores do módulo do campo obtidos estão representados na Figura 10, juntamente com o perfil litológico do piezômetro PM-5, perfurado na posição $175 \mathrm{~m}$. Observa-se ao longo do perfil uma predominância de zonas condutoras que se estendem 


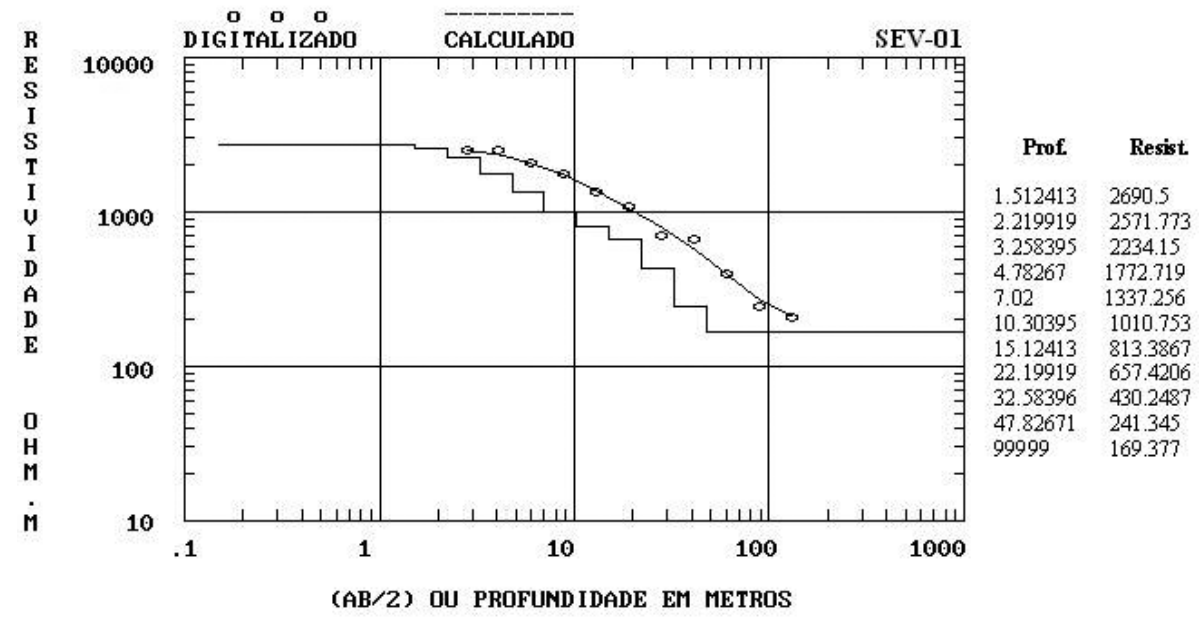

Figura 11 - Modelo interpretativo da SEV 1.

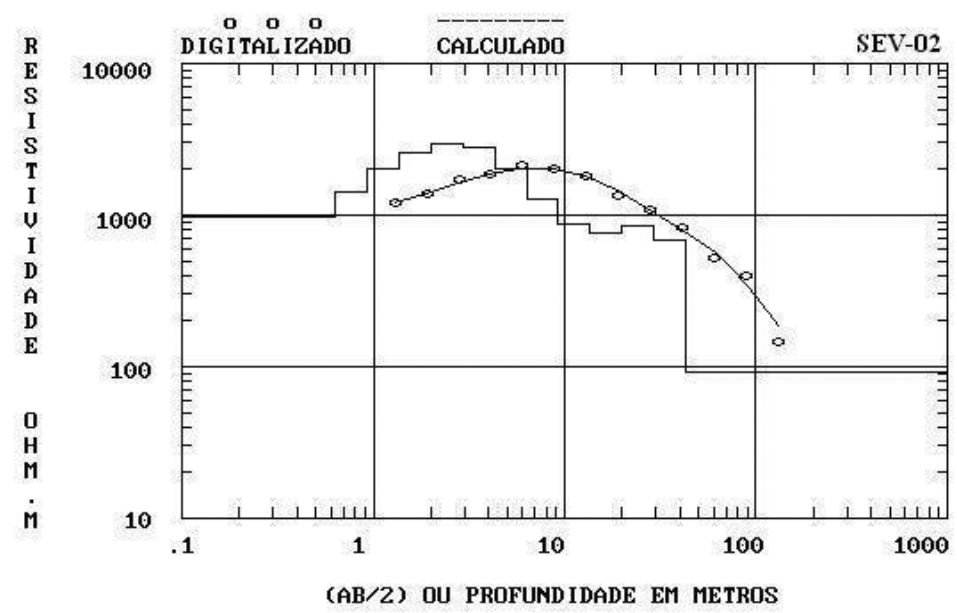

\begin{tabular}{lr}
\multicolumn{1}{c}{ Prof. } & Resist. \\
& \\
.6317999 & 975.0203 \\
.9273555 & 1410.399 \\
1.361172 & 2005.373 \\
1.997927 & 2614.235 \\
2.932556 & 2981.758 \\
4.304403 & 2780.685 \\
6.318 & 2041.743 \\
9.273557 & 1289.812 \\
13.61172 & 879.8112 \\
19.97927 & 765.8897 \\
29.32556 & 845.7485 \\
43.04404 & 676.5891 \\
99999 & 91.89079
\end{tabular}

Figura 12 - Modelo interpretativo da SEV 2.

desde as maiores frequências (menores profundidades) até as menores frequências (maiores profundidades).

A litologia do piezômetro PM-5 é essencialmente argilosa, correlacionando com o padrão eletromagnético condutivo. Observa-se ainda que os valores do módulo do campo associados ao padrão condutivo são bem elevados (os mais elevados encontrados na área), como aqueles dos perfis EM-1 e EM-4. Esses valores provavelmente receberam contribuição não só do material argiloso, como também da condutividade da água do piezômetro PM-5, que apresentou valores elevados (variando de $280,0 \mu \mathrm{S} / \mathrm{cm}$ no período chuvoso e de 233,2 $\mu \mathrm{S} / \mathrm{cm}$ no de estiagem).

\section{Medidas de resistividade}

Os modelos geoelétricos da subsuperfície obtidos a partir das SEVs estão representados nas Figuras 11 a 20. Nas figuras também aparecem os valores de resistividade aparente digitalizados durante o processamento de cada SEV (círculos) e os valores de resistividade aparente calculados para os respectivos modelos geoelétricos (linha contínua).

Na SEV 1 (Fig. 11), assim como nas SEVs 7, 8 e 9 (Figs. 17 a 19), os valores de resistividade decrescem continuamente com 0 aumento de $A B / 2$, provavelmente porque essas SEVs encontram-se mais próximas do Lago Bolonha (Fig. 2), que teria suas águas infiltrando lateralmente e em profundidade. Nas outras SEVs, à exceção da SEV 10 (Fig. 20), os valores de resistividade aparente crescem a partir da pequena separação entre os eletrodos de corrente, atingem um máximo com AB/2 entre 4 e 6 m e passam a decrescer. 0 mencionado aumento na resistividade pode ter sido causado por concreções ferruginosas frequentemente observadas nos piezômetros. 

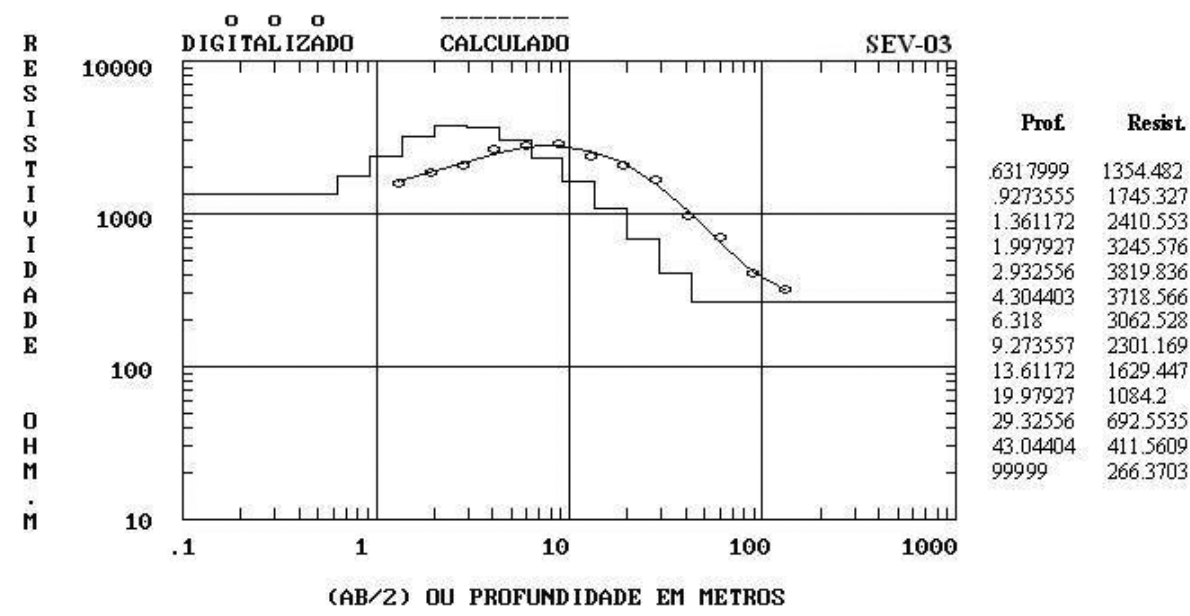

Figura 13 - Modelo interpretativo da SEV 3.

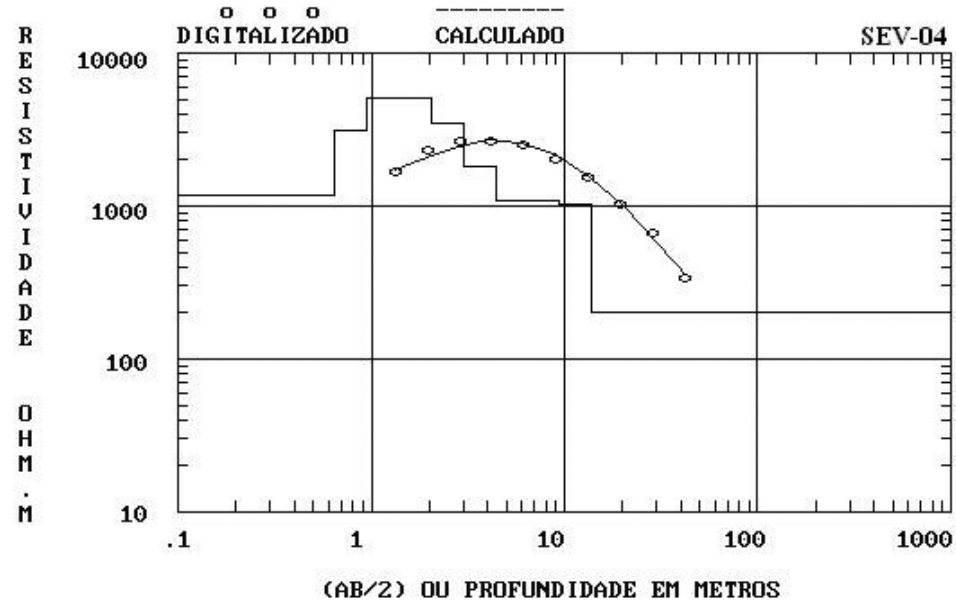

Prof. Resist. $645484 \quad 1192.126$ $947441 \quad 3112.141$ $1.390653 \quad 5033.005$ $2.0412 \quad 5122653$ $\begin{array}{ll}2.0412 & 5122.653 \\ 2.996072 & 3467.43\end{array}$ $\begin{array}{ll}2.996072 & 3467.43 \\ 4.397632 & 1807.673\end{array}$ $6.454842 \quad 1075.157$ $9.474412 \quad 1080.223$ $\begin{array}{ll}9.474412 & 1080.223 \\ 13.90654 & 1020.377\end{array}$ $99999 \quad 202.8738$

Figura 14 - Modelo interpretativo da SEV 4.

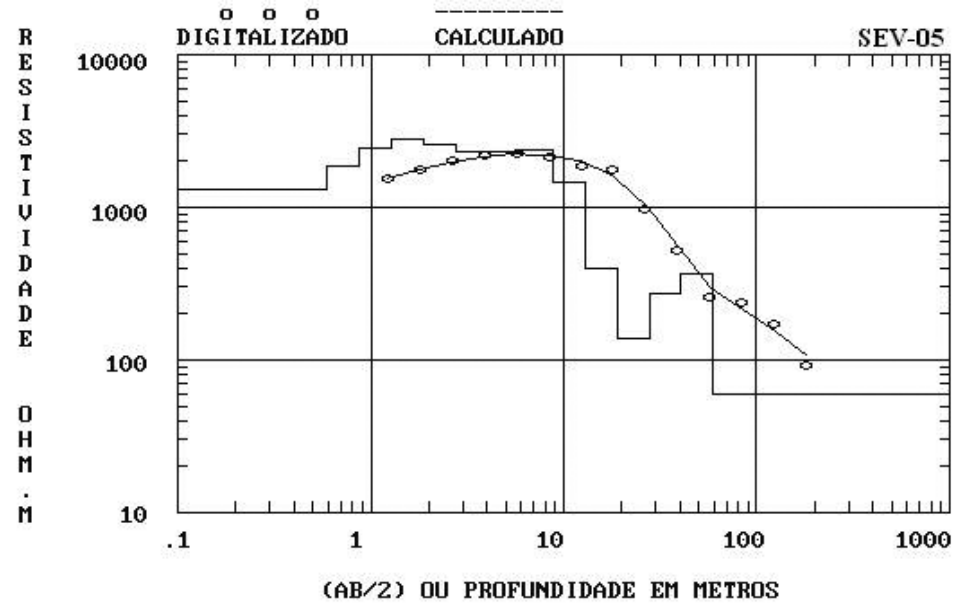

\begin{tabular}{lr}
\multicolumn{1}{c}{ Prof } & Resist. \\
& \\
.5959941 & 1296.859 \\
.8747997 & 1861.385 \\
1.28403 & 2458.209 \\
1.884699 & 2772.289 \\
2.76636 & 2612.418 \\
4.060461 & 2300.285 \\
5.959942 & 2320.118 \\
8.747998 & 2383.129 \\
12.84031 & 1478.228 \\
18.84699 & 400.8029 \\
27.6636 & 138.8726 \\
40.60461 & 272.8443 \\
59.59942 & 366.7761 \\
99999 & 59.41755 \\
&
\end{tabular}

Figura 15 - Modelo interpretativo da SEV 5. 


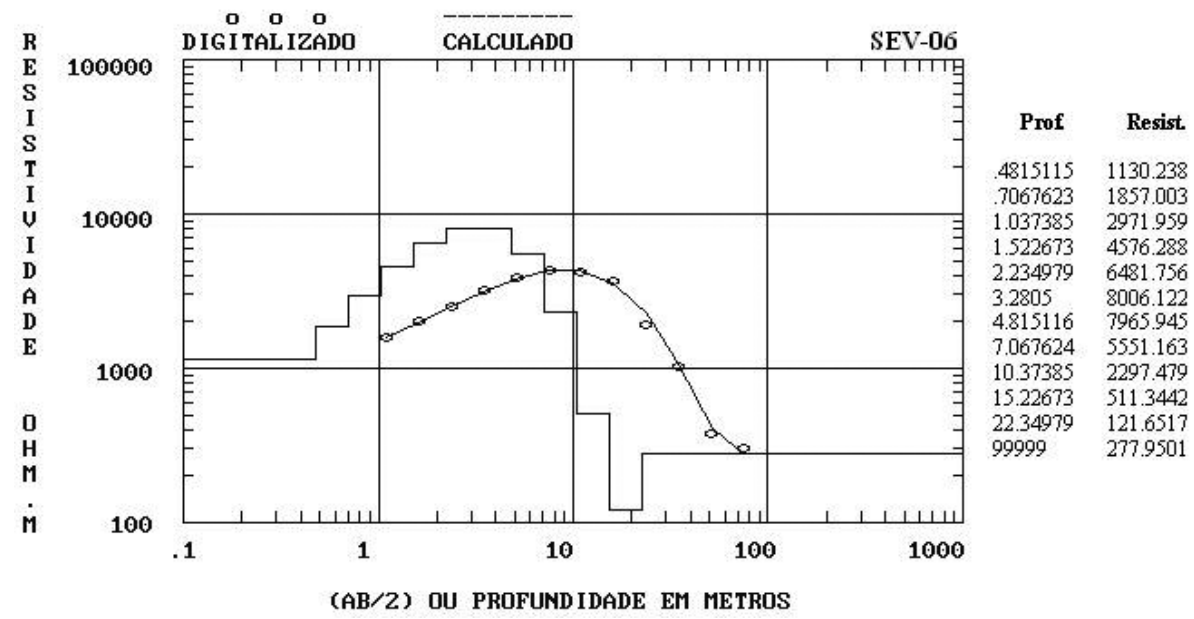

Figura 16 - Modelo interpretativo da SEV 6.

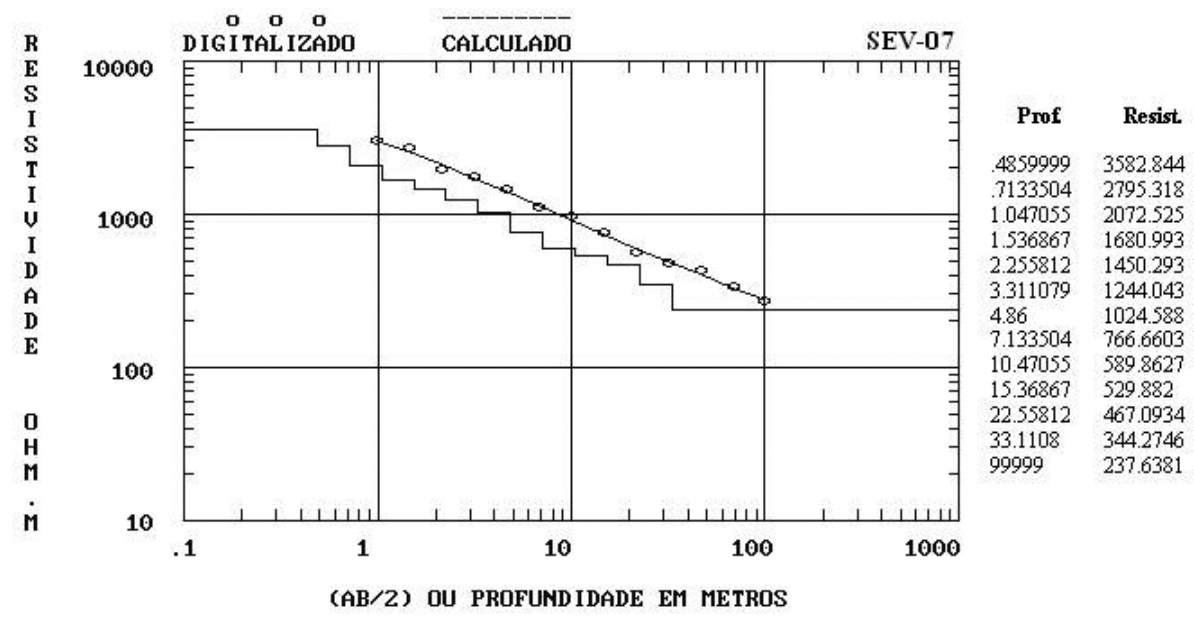

Figura 17 - Modelo interpretativo da SEV 7.

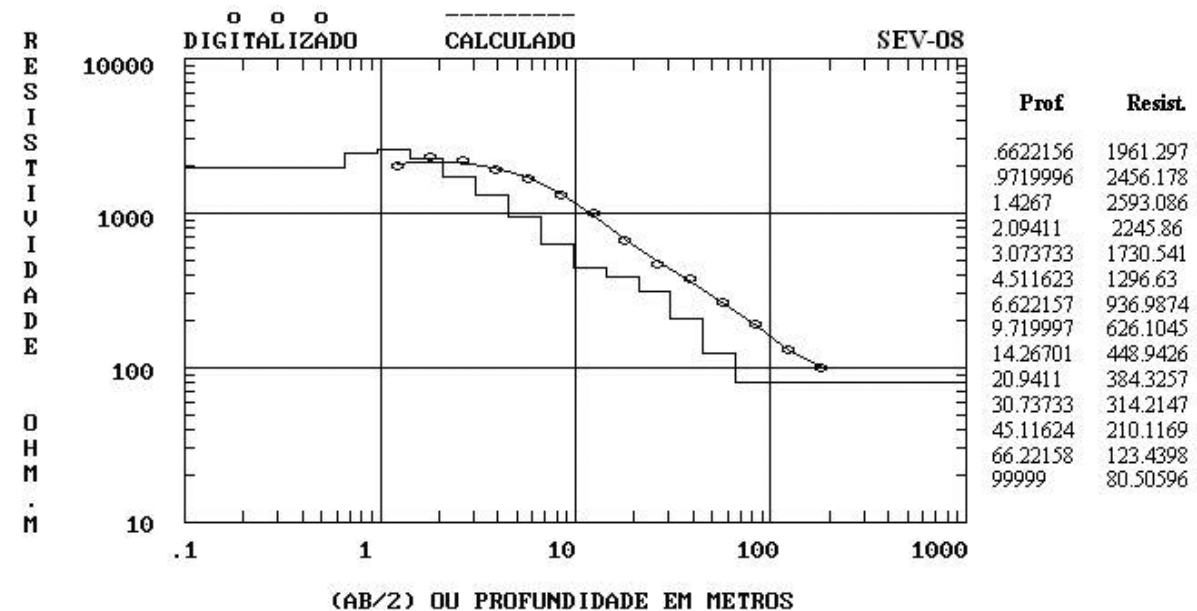

Figura 18 - Modelo interpretativo da SEV 8. 


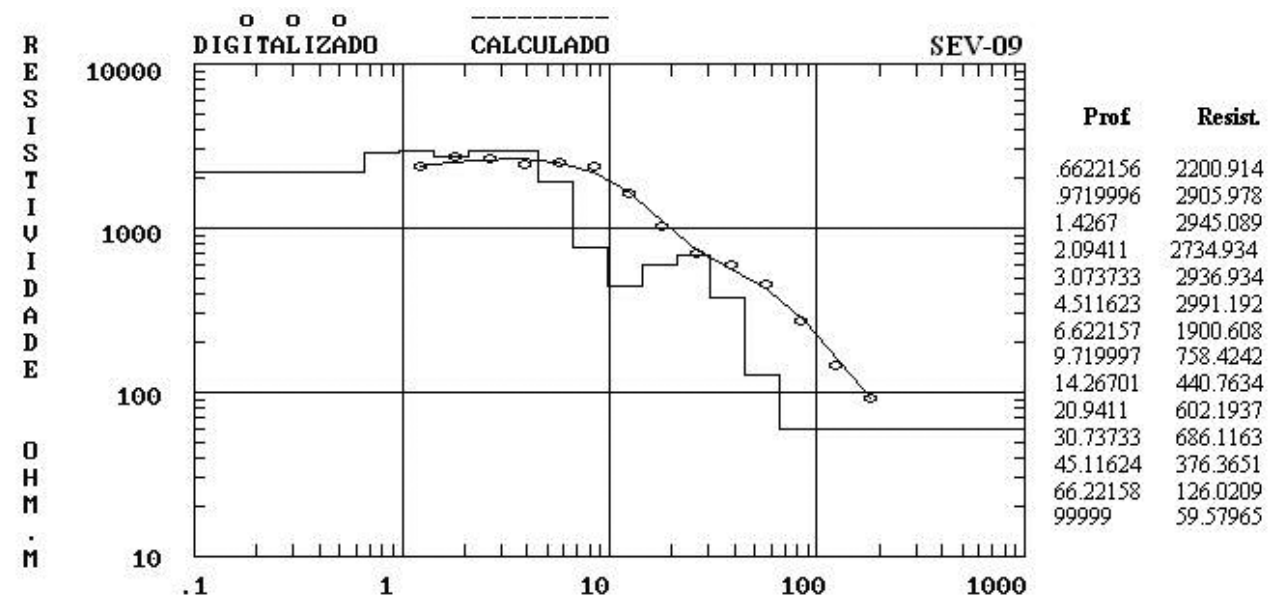

(AB/2) OU PROFUNDIDADE EM METROS

Figura 19 - Modelo interpretativo da SEV 9.

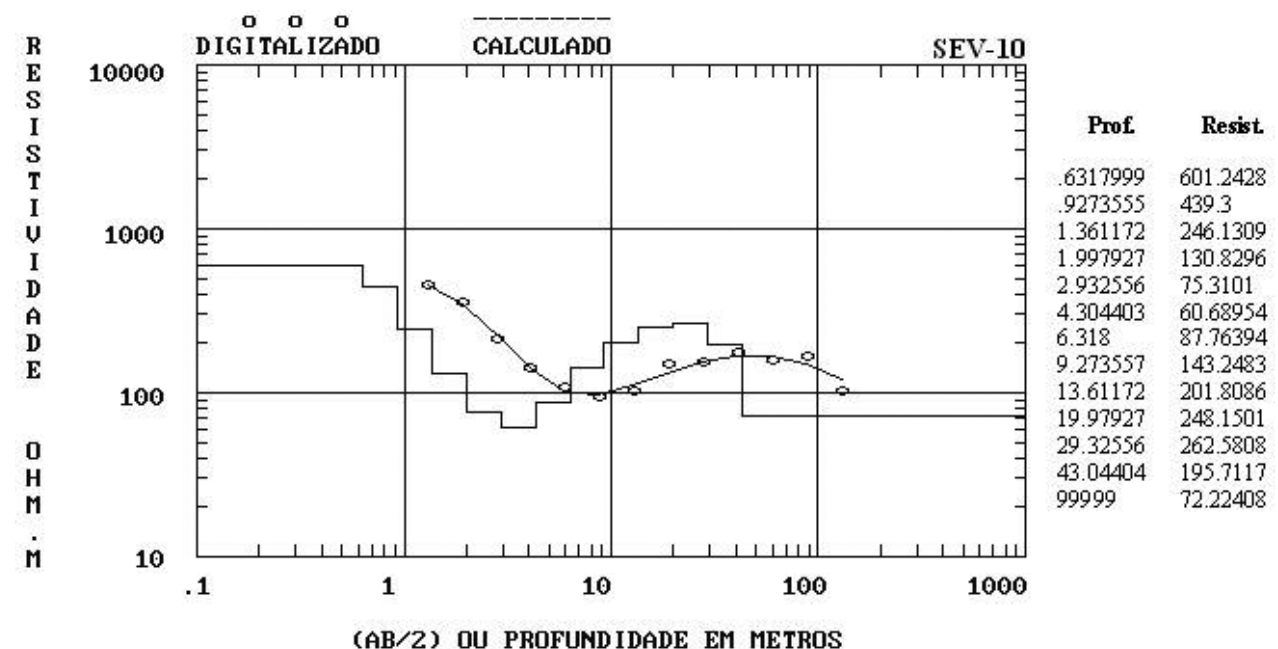

Figura 20 - Modelo interpretativo da SEV 10.

Os modelos geoelétricos das SEVs 4, 5 e 6 (Figs. 14 a 16) mostram uma queda acentuada na resistividade em torno de $10 \mathrm{~m}$ de profundidade, que pode ser associada à argila cinza observada nos piezômetros. Na SEV 2, essa queda acentuada somente ocorre à profundidade de 43 m (Fig. 12), também sugerindo argilosidade.

A SEV 10 (Fig. 20) apresenta um decréscimo acentuado de resistividade nos níveis mais rasos de profundidades (em torno de $4 \mathrm{~m}$ ), que pode estar associado ao nível freático relativamente próximo à superfície, conforme verificado no piezômetro PM-1 instalado às suas proximidades, assim como a influência de poças e lagoas formadas por águas pluviais localizadas em seu entorno.
Os modelos geoelétricos das SEVs 1, 2, 4, 7 e 10 foram correlacionados lateralmente com os perfis litológicos dos piezômetros perfurados às proximidades delas, conforme exemplificado nas Figuras 21, 22 e 23.

A correlação permitiu validar os modelos geoelétricos, já que a presença das argilas ou do nível de água faz com que os valores de resistividade diminuam, enquanto a presença de material arenoso produz aumento na resistividade.

Os modelos geoelétricos obtidos para as SEV 1,2 e 3 , realizadas ao longo do perfil EM-1, aparecem correlacionados lateralmente na Figura 24. Uma comparação dessa figura com a Figura 3 (pseudo-seção dos valores do módulo do campo para o perfil EM-1) mostra uma boa relação entre as medidas eletromagnéticas e de resistividade. 

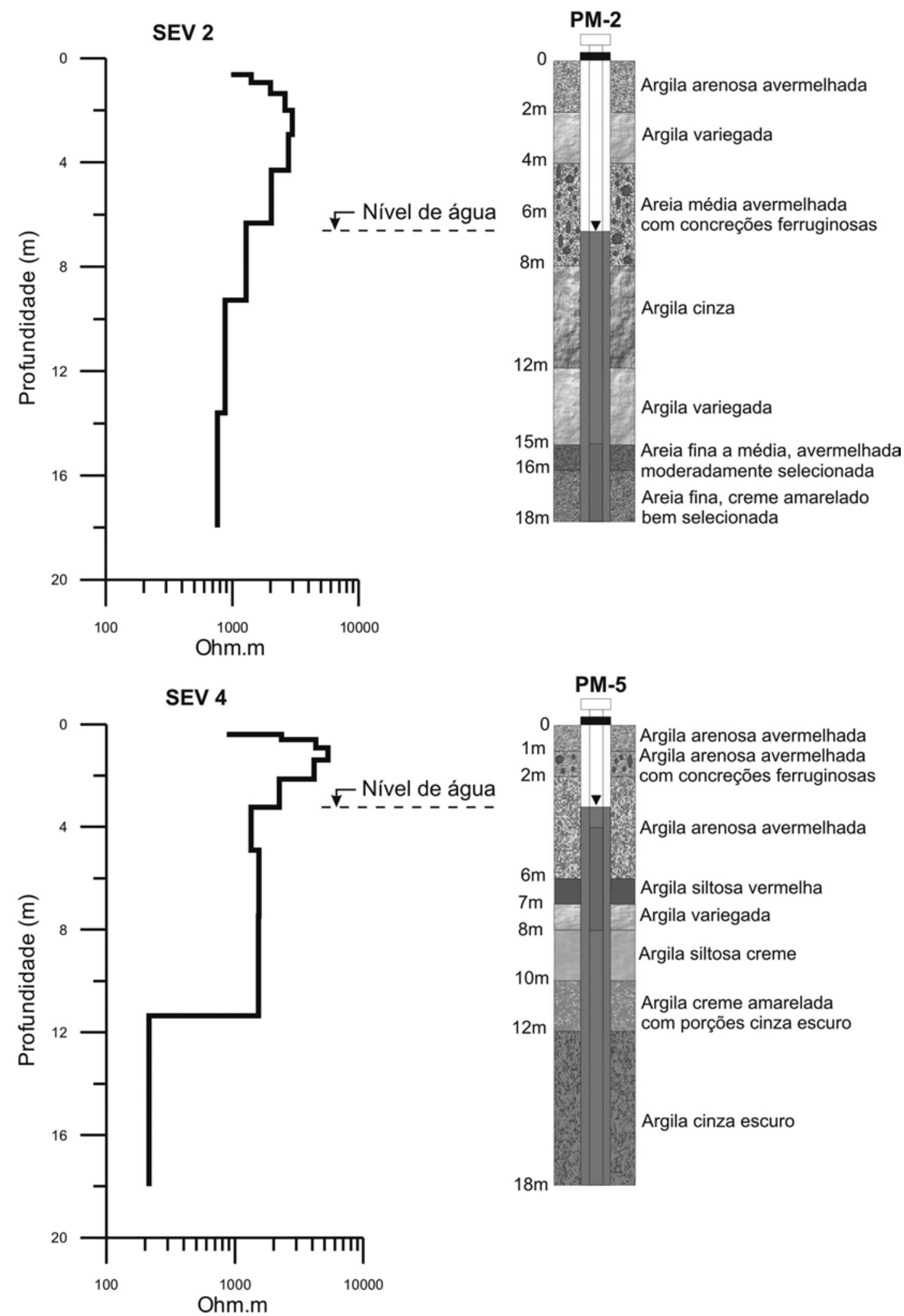

PM-5

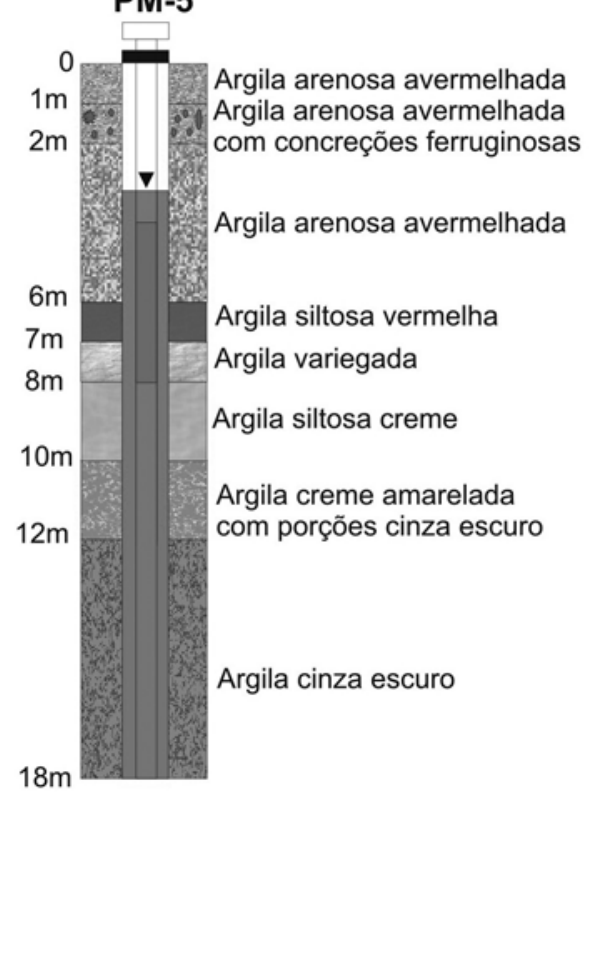

Figura 21 - Correlação dos modelos interpretativos das SEVs 2 e 4 com a litologia dos piezômetros PM-2 e PM-5. A SEV 2 e o piezômetro PM-2 estão separados por menos de 20 m, assim como a SEV 4 e o piezômetro PM-5. 

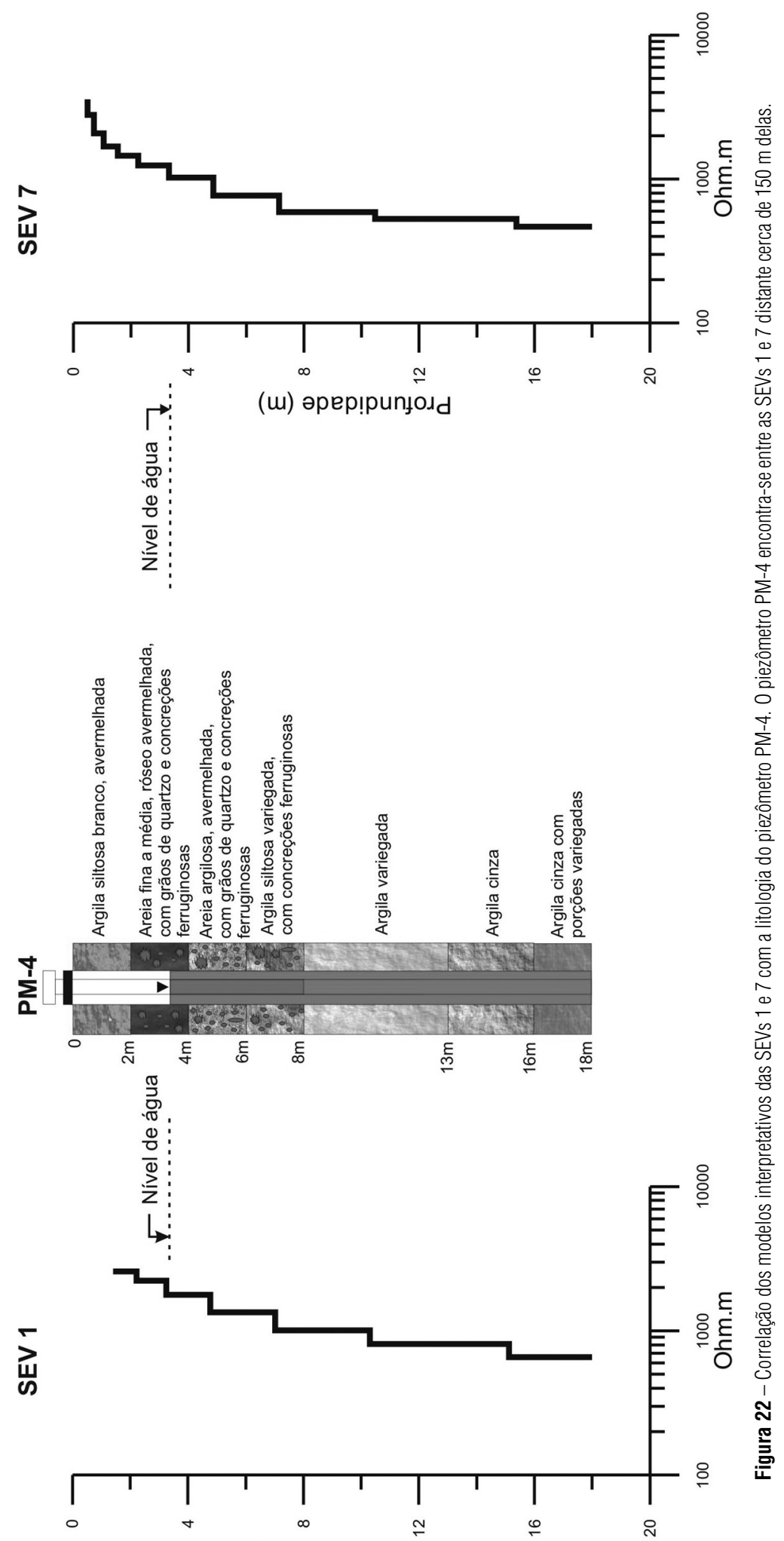

(ui) әpep!punjold 


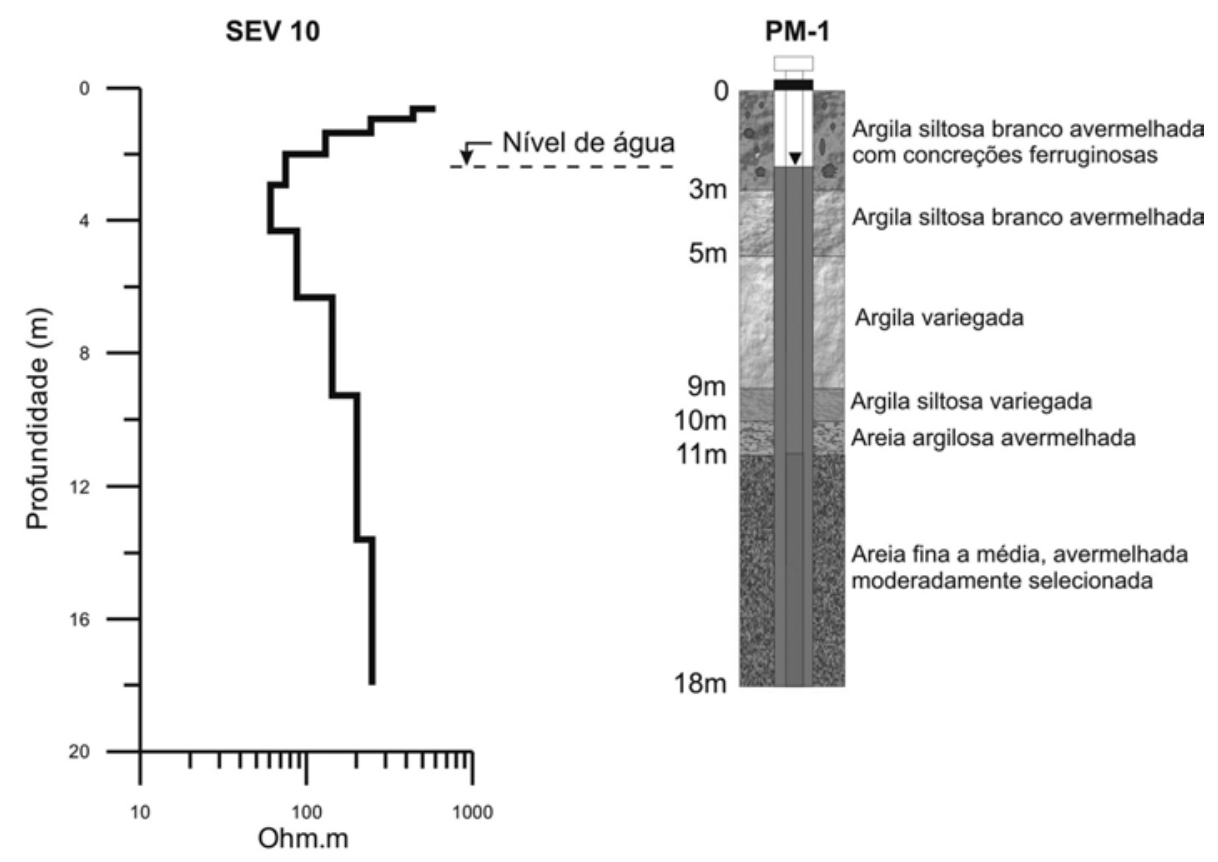

Figura 23 - Correlação do modelo interpretativo da SEV 10 com a litologia do piezômetro PM-1, com uma distância entre ambos em torno de 75 m.

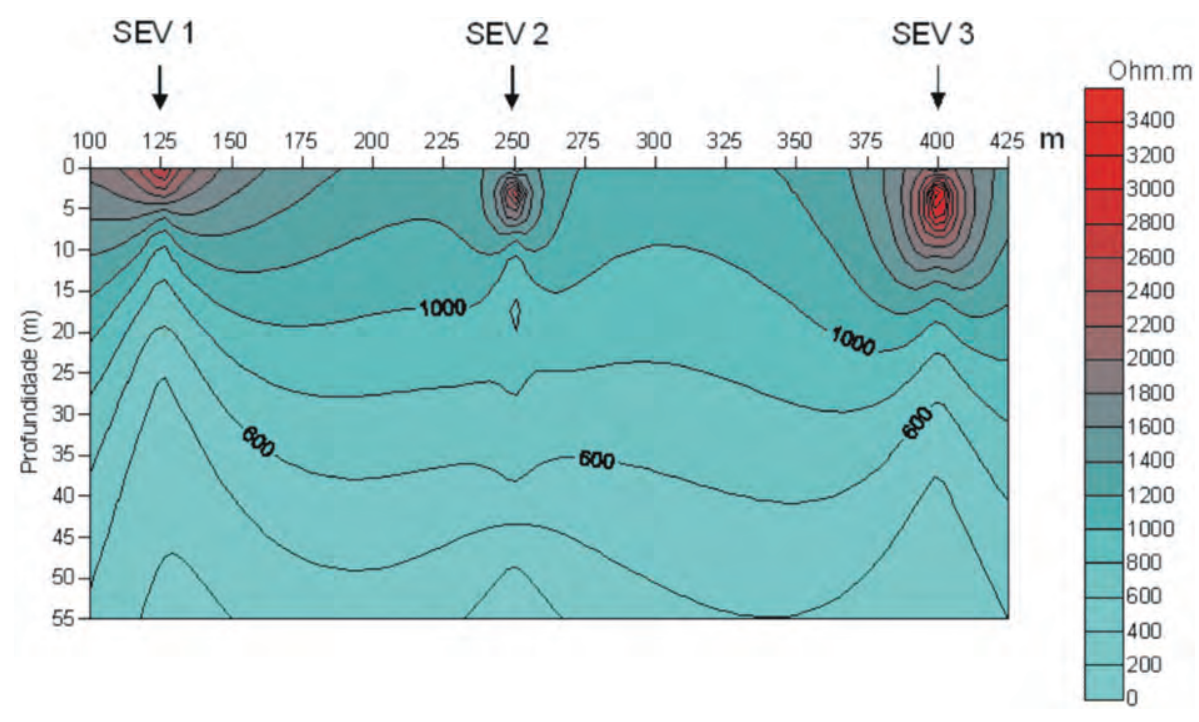

Figura 24 - Correlação lateral dos modelos geoelétricos das SEVs 1, 2 e 3 realizadas sobre o perfil EM-1.

\section{CONCLUSÕES}

Os resultados das medidas geofísicas realizadas na área do PEUt apresentaram uma excelente concordância com as informações geológicas provenientes dos piezômetros.

As medidas eletromagnéticas realizadas na área de trabaIho evidenciaram a presença de camadas geológicas com ca- racterísticas elétricas diferentes (condutividade) que refletiram a presença de zonas condutoras (material argiloso) e zonas resistivas (material arenoso).

Há uma predominância de material arenoso, principalmente nos perfis 2, 3, 5 e 8 e nos demais a de material argiloso, mostrando variações litológicas ao longo dos perfis estudados. De acordo com as informações litológicas dos piezômetros, 
se tratam de argilas de coloração avermelhada, variegadas e esbranquiçadas e areias de granulometria que correspondem à fração fina e média, além da presença de concreções ferruginosas, sedimentos que estão relacionados ao Pós-Barreiras.

A representação dos valores medidos do módulo de campo versus frequência, permitiu uma melhor visualização da distribuição das zonas condutoras lateralmente e com a profundidade, exibindo uma pseudo-seção da subsuperfície.

Essa imagem aparente da subsuperfície (pseudo-seção) ao ser correlacionada com a distribuição dos sedimentos amostrados dos piezômetros perfurados sobre os perfis de medidas ou próximo deles, mostraram-se eficientes na delimitação das zonas arenosas e argilosas da subsuperfície, indicando que as variações de condutividade detectadas pelo método eletromagnético são melhores correlacionadas às variações litológicas ou à presença de água, do que à contaminação.

Além disso, a comparação entre as pseudo-seções indica ainda, um aumento na argilosidade da subsuperfície em direção à zona residencial adjacente ao PEUt, sugerindo que os lagos possuem chances de estarem protegidos de contaminações geradas na zona residencial.

Os modelos interpretativos das SEVs ao serem comparados com a litologia dos piezômetros, indicaram que as argilas mais superficiais apresentam elevada resistividade e podem ser confundidas com material arenoso na interpretação geofísica. Os modelos geoelétricos obtidos a partir das SEVs mostraram boa correlação com as pseudo-seções das medidas eletromagnéticas indicando as zonas argilosas e arenosas.

\section{AGRADECIMENTOS}

Os autores agradecem ao CPGG e à Faculdade de Geofísica da UFPA, à Universidade do Estado do Pará (UEPA), à Universidade Federal da Bahia (UFBA) e à Secretaria de Meio Ambiente do Pará (SEMA) pela infraestrutura e apoio oferecidos na realização dos trabalhos. Assim como, ao Conselho Nacional de Desenvolvimento Científico e Tecnológico (CNPq) pelo financiamento dos estudos através dos projetos de pesquisa "Caracterização socioeconômica e ambiental integrada do sistema de abasteci- mento de água potável da cidade de Belém-PA" (Processo No. 505247/2004-6), "Estudo Hidrogeológico da Bacia Hidrográfica do Utinga" (Processo No. 476413-2004-4) e "Avaliação hidrogeoquímica do sistema hídrico na área de abrangência do Parque Ambiental de Belém-PA" (Processo No. 471041/2006-8).

\section{REFERÊNCIAS}

ABNT. Associação Brasileira de Normas Técnicas. 1997. NBR 13895 Construção de poços de monitoramento e amostragem. 21 p.

BENSON AK, PAYNE KL \& STUBBEN MA. 1997. Mapping groundwater contamination using DC resistivity and VLF geophysical methods - A case study. Geophysics, 62(1): 80-86.

FARIAS E dos S, NASCIMENTO FS do \& FERREIRA MAA. 1992. Mapeamento da área Belém-Outeiro. Estágio de campo III. Relatório Final. UFPA. 247 p.

IBGE. Instituto Brasileiro de Geografia e Estatística. 2010. Estimativa do universo populacional. Recenseamento geral do Brasil. Rio de Janeiro. Disponível em: <http://www.ibge.gov.br/cidadesat/topwindow.htm?1>. Acesso em: 28 jul. 2010.

IDESP. Instituto de Desenvolvimento Econômico Social do Pará. 1980. Projeto reconhecimento dos recursos naturais da Região Metropolitana de Belém. Reconhecimento hidrogeológico. Anexo I. 11 p.

LIMA OAL, SATO HK \& PORSANI MJ. 1995. Imaging industrial contaminant plumes with resistivity techniques. J. Appl. Geophysics, 34: 93-108.

SILVA RCS. 2002. Aplicação dos métodos geofísicos elétrico e eletromagnético na determinação de unidades sedimentares costeiras tropicais em Bragança, nordeste do Pará. Dissertação de Mestrado, Centro de Geociências, Universidade Federal do Pará. 55 p.

VIEIRA LS \& SANTOS PCT. 1987. Amazônia: seus solos e recursos naturais. São Paulo. Agronômica Ceres. 416 p.

WARD SW (Ed.). 1990. Geotechnical and Environmental Geophysics. Investigation in Geophysics 5, Soc. Expl. Geophysics. Tulsa. 300 p.

ZOHDY AA \& BISDORF RJ. 1989. Programs for the Automatic Processing and Interpretation of Schlumberger Sounding curves in Quickbasic 4.0. Open-File Report 89 - 137 A\&B, U. S. Geological Survey, 19 p. 


\section{NOTAS SOBRE OS AUTORES}

Vânia Eunice Bahia. Graduada em Licenciatura e Bacharelado em Geografia (1996) e Mestre em Geociências com ênfase em Hidrogeologia Ambiental (2003) pela Universidade Federal do Pará. Possui doutorado pela Universidade Federal da Bahia na área de Geologia Ambiental, Hidrogeologia e Recursos Hídricos. Atua como pesquisadora no grupo de pesquisa Amazônia 21 da Universidade Federal do Pará. Tópicos de interesse: Hidrogeologia, Geologia Ambiental, gestão de recursos hídricos e Geologia Regional.

José Gouvêa Luiz. Geólogo formado pela Universidade Federal do Pará, Mestre em Geofísica pela Universidade Federal da Bahia e Doutor em Geofísica pela Universidade Federal do Pará. Atualmente é professor associado da Faculdade de Geofísica da Universidade Federal do Pará, onde desenvolve atividades de ensino e pesquisa. Tópicos de interesse: Geofísica aplicada ao meio ambiente; Geofísica aplicada à Arqueologia e Aplicação de métodos geofísicos na exploração de água subterrânea.

Luiz Rogério Bastos Leal. Graduado em Geologia pela Universidade Federal da Bahia (1988), Mestre (1992) e Doutor (1998) em Geologia pela Universidade de São Paulo. Pós-doutorado em Hidrogeologia na Universidade do Texas (Estados Unidos) em 2006. Atualmente é professor adjunto IV e vice-reitor da Universidade Federal da Bahia e pesquisador visitante da University of Texas at San Antonio - Centre of Water Research. Tópicos de interesse: Hidrogeologia, Geologia Ambiental, gestão de recursos hídricos e Geologia Regional.

Norbert Fenzl. Graduado em Geologia (1971), Doutor em Hidrogeologia (1975) e Pós-Doutor (1993) pela Universidade de Viena. Atualmente é pesquisador e professor associado III da Universidade Federal do Pará e Coordenador Técnico do Projeto GEF/Amazonas, executado pelo PNUMA e pela OTCA, financiado pelo GEF (Global Environmental Facility). Tópicos de interesse: Geociências e Ecologia, com ênfase em Ciências Ambientais, nos temas desenvolvimento sustentável, Amazônia, meio ambiente e teoria de sistemas.

Gundisalvo Piratoba Morales. Graduado em Licenciatura em Química - Universidad Pedagógica y Tecnológica de Colombia (1981), possui mestrado e doutorado em Geologia e Geoquímica pela Universidade Federal do Pará (1998 e 2002). Atualmente é professor do curso de Engenharia Ambiental da Universidade do Estado do Pará e do Centro Federal de Educação Tecnológica do Pará. Atua como pesquisador do grupo de Pesquisa Amazônia 21 da Universidade Federal do Pará e é líder do grupo de pesquisa Amazônia Global da Universidade do Estado do Pará. Tópicos de interesse: avaliação e impactos ambientais, Hidrogeologia, resíduos sólidos, análises instrumentais e Química Ambiental. 